\title{
Differential soil moisture pulse uptake by coexisting plants in an alpine Achnatherum splendens grassland community
}

\author{
Huawu $\mathrm{Wu}^{1,2,3} \cdot$ Xiao-Yan $\mathrm{Li}^{1,2} \cdot \operatorname{Jing} \mathrm{Li}^{4,5} \cdot$ Zhiyun Jiang ${ }^{2} \cdot$ Huiying Chen ${ }^{1,2}$. \\ Yujun $\mathrm{Ma}^{1,2} \cdot$ Yongmei Huang ${ }^{1,2}$
}

Received: 16 July 2015/Accepted: 2 May 2016/Published online: 19 May 2016

(C) Springer-Verlag Berlin Heidelberg 2016

\begin{abstract}
The niche differentiation of resources among coexisting plants commonly reflects the fundamental functions of plant coexistence in water-limited ecosystems. However, the dynamics of water use patterns by coexisting plants that respond to soil moisture pulses are scarcely known in the semiarid alpine ecosystems of the QinghaiTibetan Plateau, particularly for deep-rooted grasses such as Achnatherum splendens in the Qinghai Lake watershed. Hence, we used the stable deuterium isotope method to detect the potential water sources for A. splendens during two growing seasons of 2013 and 2014. Our results indicate that SWC and $\delta \mathrm{D}$ values of shallow soil layer $(0-10 \mathrm{~cm})$ showed the highest variations in comparison with those in other soil layers during the growing seasons due to the combined effect of evaporation and precipitation inputs. A. splendens depended largely on shallow soil water availability at the early growing season. At the peak of the growing season, this deep-rooted grass A. splendens and shallow-rooted grass Leymus chinensis showed a high
\end{abstract}

Xiao-Yan Li

xyli@bnu.edu.cn

1 State Key Laboratory of Earth Surface Processes and Resource Ecology, Beijing Normal University, Beijing 100875, China

2 College of Resources Science and Technology, Beijing Normal University, Beijing 100875, China

3 State Key Laboratory of Lake Science and Environment, Nanjing Institute of Geography and Limnology, Chinese Academy of Sciences, Nanjing 210008, China

4 Institute of Geographic Sciences and Natural Resources Research, Chinese Academy of Sciences, Beijing 100101, China

5 University of Chinese Academy of Sciences, Beijing 100049, China degree of response in the water use source to the changes in soil moisture pulses and shifted their water source from shallow to deep soil layer because water in the shallow soil layer became less available due to a long-time rainless days with strong evaporation effect on the shallow soil layer. In contrast, shallow soil water was utilized by all coexisting plants owing to an abrupt increase in shallow SWC with large events or long-lasting small events. At the late growing season, A. splendens used water from the shallow $(0-10 \mathrm{~cm})$ and middle soil layer $(10-30 \mathrm{~cm})$, while $L$. chinensis mainly relied on the shallow soil layer water. Comparatively, shallow-rooted herbs (Heteropappus altaicus and Allium tanguticum) predominantly used water from the shallow soil layer $(0-10 \mathrm{~cm})$ over the entire growing seasons regardless of soil water availability. Overall, the contrasting water use patterns by coexisting plants demonstrate their adaptations to the fluctuations of soil moisture pulses in water-limited ecosystems.

Keywords Stable isotopes - Soil water availability · Precipitation pulse - Mixing isotope IsoSource model . Interspecific competition

\section{Introduction}

Water is one of the most important factors that determines the plant primary productivity, distribution and ecosystem metabolic activity (e.g., photosynthesis and respiration) in terrestrial ecosystems (Noy-Meir 1973; Chesson et al. 2004; Ludwig et al. 2005; Xu and Li 2006; Jenerette et al. 2008). Precipitation is the main water source for plants in semiarid and arid regions. However, uneven and stochastic precipitations usually cause spatiotemporal changes in the soil water availability (Noy-Meir 1973) and, thus, shape 
the plant acclimation traits because of periodic or persistent water stresses (Ramírez et al. 2009). Previous studies have shown that deep-rooted plants have the ability to exploit a deep or dependable water source than enables them to survive long periods without rain or to overcome seasonal water limitations (Dodd et al. 1998; Rossatto et al. 2012; Dai et al. 2015; Wu et al. 2016). In contrast, shallow-rooted plants mainly rely on the soil water recharge from precipitation pulses (Ehleringer et al. 1991; Williams and Ehleringer 2000; Yang et al. 2011). The contrasting ability of plants to extract available soil moisture is largely associated with precipitation pulse time, intensity and amount during the growing season. Therefore, explorations of water use patterns by coexisting plants associated with soil moisture pulses in arid and semiarid regions are necessary for understanding the relationships between plants and precipitation pulses.

In arid and semiarid regions, the vegetation patterns are commonly characterized by a two-phase mosaic structure of bare and vegetated patches consisting of shrub or grass (Montaña et al. 1995; Aguiar and Sala 1999). Bare and vegetated patches behave as differential water use patterns to better adjust to variable environments (Dodd et al. 1998; Ludwig et al. 2005; Ramírez et al. 2009). Previous studies have noted that the typically differential resource partitioning among patchy vegetation combined with disturbance (e.g., fire or overgrazing) and drought caused the loss or death of dominant grass species, or the replacement of desirable grass species with undesirable shrubs or toxic grasses. Examples of this dynamics occur in savanna regions (Kulmatiski and Beard 2013) and in the grassland of northwestern China affected by desertification (Cheng et al. 2006). Although other studies mainly focused on the water source partitioning of shrub patches and interspersed grasses (Ehleringer et al. 1991; Snyder et al. 2004), little research has been conducted on the water use patterns of deep-rooted grass patches and other associated grasses and herbs, especially in semiarid and alpine grassland ecosystems of the Qinghai-Tibetan Plateau. There are large areas of A. splendens grasslands with a two-phase mosaic spatial distribution in the Qinghai Lake watershed. To date, the degenerated areas of $A$. splendens grasslands with a decreased plant species diversity result in a marked decline in the productivity, which is largely attributed to anthropogenic disturbances (e.g., overgrazing and overexploiting) (Zhou et al. 2002; Huai et al. 2008). Nonetheless, the effects of highly variable soil moisture pulses of water use in grass patches and associated species have been largely ignored in the Qinghai Lake watershed. Likewise, whether this effect can be exerted on the distribution of grass patches and associated species is still unclear. Hence, their is a need to investigate how water use patterns by A. splendens and other associated species (grasses and herbs) respond to the soil moisture pulses of highly variable precipitation in the alpine grassland of Qinghai Lake watershed.

In this study, we analyzed the stable compositions of potential soil water sources and xylem water during two consecutive growing seasons. The objectives of this study were (1) to characterize the dynamic variations of the soil water content and the isotopic composition of soil water and (2) to examine the effect of the events' size and length of rainless days events before each sampling date on soil moisture pulse used by coexisting plants in an alpine grassland ecosystem. This study will better explain the interspecific competition for the soil moisture pulses among coexisting species and predict the future grassland species dynamics under the current climate change scenario.

\section{Study site description}

The study site $\left(100.19^{\circ} \mathrm{E}, 37.24^{\circ} \mathrm{N}, 3217 \mathrm{~m}\right.$ above sea level) is located in the lower stretch of the Shaliu River basin, north of the Qinghai Lake, and approximately $2 \mathrm{~km}$ away from the Sanjiaocheng Sheep Breeding Farm (SSBF; Fig. 1a). The region corresponds to a semiarid, cold and alpine climate zone dominated by the East Asian monsoon during the growing season. The mean annual temperature of the drainage basin is $0.1{ }^{\circ} \mathrm{C}$, and the mean annual precipitation is approximately $400 \mathrm{~mm}$, with more than $65 \%$ of the precipitation falling between June and September. The mean annual evaporation is approximately $1300 \mathrm{~mm}$, with over $65 \%$ of it occurring during the warm summer season (Chen and Peng 1993; An et al. 2012).

The A. splendens grassland is distributed around the Qinghai Lake (Fig. 1a) and plays a vital role in the environmental protection and conservation of water and soil (Huai et al. 2008). Lacustrine plains, valley terraces and piedmont ramps ranging from 2900 to $3400 \mathrm{~m}$ a.s.l. are known to be suitable habitats for this grass species. Livestock fences have been established since the 1980s to protect the A. splendens grassland from overgrazing in the study site, which is used as a winter and spring grazing pasture for yak and sheep from February to late June. The community structure within the study site is characterized by two distinctive vegetation layers. The overstory layer is composed of a single species, A. splendens, a perennial and deep-rooted tussock tallgrass. The understory layer is dominated by perennial and shallow-rooted species with mixed herbs such as Agropyron cristatum, Carex ivanovae, Heteropappus altaicus, Allium tanguticum, and grasses such as Stipa breviflora and Leymus chinensis that enclose A. splendens tussocks (Fig. 1b). According to our field data, the average overall coverage of the overstory and understory layers is $8 \%(5 \mathrm{~m} \times 5 \mathrm{~m})$ and $56 \%$ 

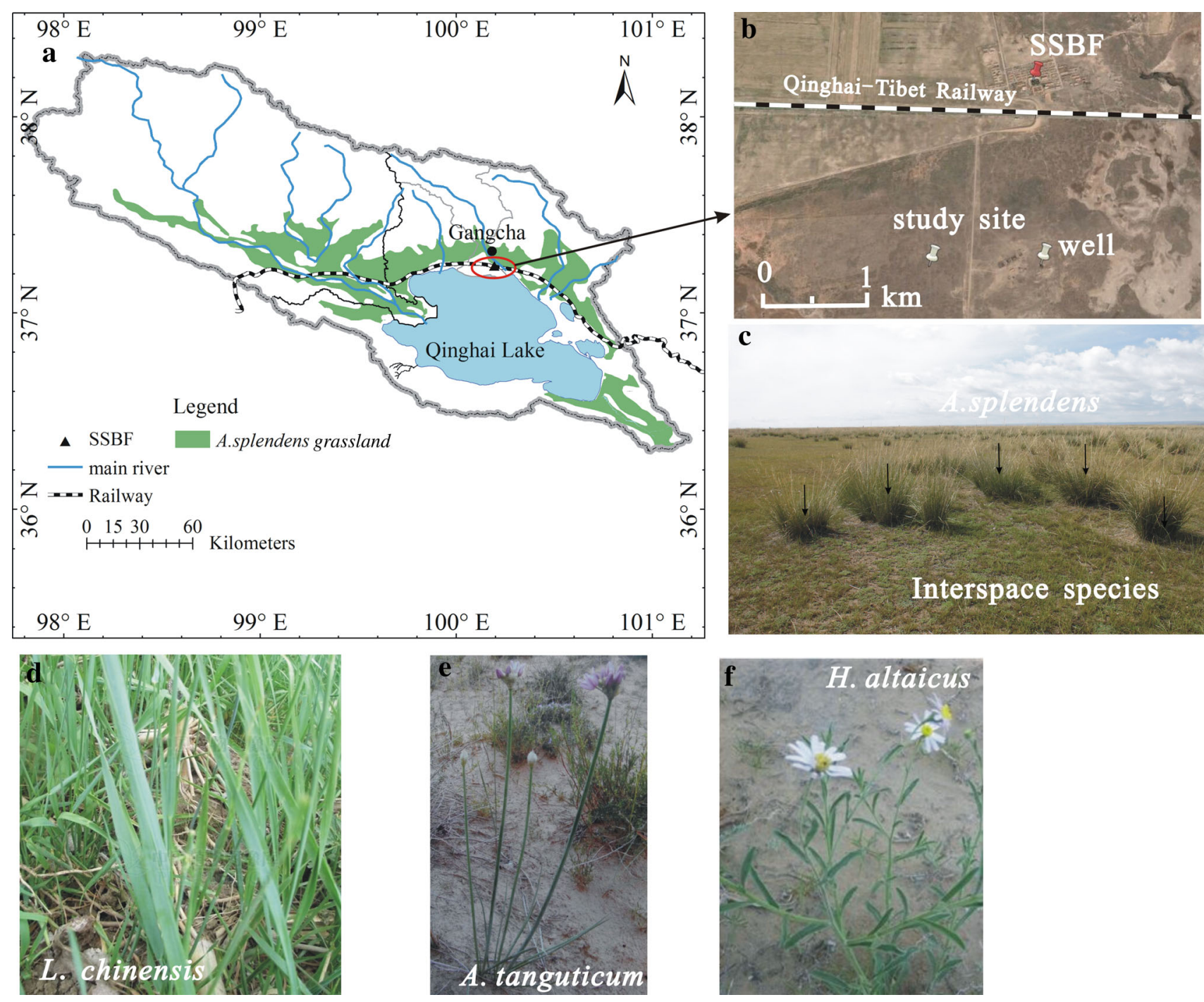

Fig. 1 Geographic location of the study region (SSBF: Sanjiaocheng Sheep Breeding Farm) and the Qinghai Lake watershed. The green area represents the distribution of the A. splendens grassland around

$(1 \mathrm{~m} \times 1 \mathrm{~m})$, respectively. The soil has mainly a silty loam texture with high spatial heterogeneity. The soil depth is approximately $60-100 \mathrm{~cm}$ with an average porosity of $27.8 \%$. The average composition is $4.5 \%$ of clay, $55.4 \%$ of silt and $40.1 \%$ of sand. The soil nutrients are mainly concentrated in the shallow soil layer $(0-10 \mathrm{~cm})$ with high contents of SOM, C and N (Table 1).

\section{Materials and methods}

\section{Field sample collections}

Seventy-eight event-based precipitation samples were collected from April to September in 2013 and 2014 at the the Qinghai Lake (a). Location of the study site (b). Photograph of the landscape pattern of the A. splendens grassland (c), H. altaicus (d), A. tanguticum (e) and L. chinensis (f) in the study site

Sanjiaocheng Sheep Breeding Farm (SSBF). The rainwater collector was constructed with a 10-cm-diameter funnel connected to a glass bottle. Each sample was collected as soon as the precipitation events stopped. Additionally, we recorded the precipitation volume, air temperature and precipitation patterns based on data from the automatic weather station within the study site. Snow samples were collected and sealed in a plastic bag and then kept at room temperature until they were completely melted. All the precipitation samples were transferred into clean polyethylene bottles $(30 \mathrm{ml})$ sealed with parafilm.

The plant phenology in the study site is constrained by a short growing season from early June to late September. Plants began to turn green when the air temperature and rainfall gradually became advantageous for plant growth 
Table 1 Description of soil properties in the study site. Particle size: clay: $<0.0002 \mathrm{~mm}$, silt: $0.0002-0.05 \mathrm{~mm}$, sand: $0.05-2 \mathrm{~mm}$

\begin{tabular}{lllllllll}
\hline Depth $\mathrm{cm}$ & SOM $(\mathrm{g} / \mathrm{kg})$ & $\mathrm{N}(\%)$ & $\mathrm{C}(\%)$ & Porosity $(\%)$ & Clay & Silt & Sand & Soil texture \\
\hline 10 & 48.5 & 0.26 & 3.29 & 57 & 3.49 & 58.9 & 37.7 & Silty loam \\
20 & 28.7 & 0.22 & 2.71 & 65 & 3.47 & 58.8 & 37.7 & Silty loam \\
30 & 25.6 & 0.18 & 2.80 & 60 & 5.29 & 55.7 & 39.0 & Silty loam \\
40 & 21.4 & 0.13 & 2.43 & 56 & 4.37 & 56.4 & 39.2 & Silty loam \\
60 & 14.7 & 0.09 & 2.27 & 51 & 5.88 & 47.4 & 46.7 & Loam \\
\hline
\end{tabular}

SOM soil organic matter
Table 2 Information of sampling plants during two consecutive growing seasons

\begin{tabular}{llll}
\hline Species & Family & Life form & Height $(\mathrm{cm})$ \\
\hline Achnatherum splendens & Gramineae & Grass & $65-100$ \\
Heteropappus altaicus & Compositae & Herb & $10-20$ \\
Allium tanguticum & Liliaceae & Herb & $15-40$ \\
Leymus chinensis & Gramineae & Grass & $15-60$ \\
\hline
\end{tabular}

(e.g., from early June). Three experimental plots of $10 \mathrm{~m} \times 10 \mathrm{~m}$ were selected in the study site, and each plot contained twenty A. splendens tussocks with other associated species. Four coexisting plant species with three replicates per species were randomly selected in each plot (Table 2; Fig. 1). These species included the dominant deep-rooted tallgrass (A. splendens) and associated shallow-rooted grass, L. chinensis, and herbs such as $H$. altaicus and A. tanguticum. The plant and soil samplings were simultaneously performed after precipitation of different event sizes during two consecutive growing seasons (Fig. 2). On each sampling date for grasses and herbs, we dug up and collected the root crown because the isotopic contents from the root crown have been well evaluated for the water source without an isotope fractionation (Barnard et al. 2006). To prevent the effect of evaporation on the isotopic contents, all the plant samples were immediately put into screw-cap glass vials and then sealed with parafilm and stored in the refrigerator $\left(-10^{\circ} \mathrm{C}\right)$ until the water extraction using cryogenic vacuum distillation was performed (West et al. 2006). The groundwater was weekly sampled from a herdsman's well from May to September in the study site.

Concurrently with the plant tissue sampling, the soil water samples were collected using a hand auger to the achievable depth $(60 \mathrm{~cm})$ at $10-\mathrm{cm}$ intervals. Subsequently, the soil water samples were divided into two parts: One was stored in the refrigerator for the isotopic analysis and the other for a subsequent gravimetric soil water content analysis (SWC, \%), which was determined by oven drying at $105{ }^{\circ} \mathrm{C}$ for $24 \mathrm{~h}$. Meanwhile, the volumetric soil water content was measured continuously during the growing seasons using $\mathrm{ECH}_{2} \mathrm{O}$ 5TE sensors (Decagon Devices, Pullman, Washington, USA) at four soil depths (10, 20, 40, $60 \mathrm{~cm}$ ) in the study site. The data were logged into a Decagon's Em50 data logger at 10-min intervals.

\section{Isotopic analysis}

Water samples from plant tissues and soil water were extracted with a cryogenic vacuum distillation system (West et al. 2006). We routinely weighed and oven-dried the extracted samples to ensure that the extraction time was long enough to vaporize the water within plant tissues and soil. The isotopic composition of all the liquid samples, e.g., precipitation, extracted from plant tissues and soil, was analyzed by an Isotopic Ratio Infrared Spectroscopy (IRIS) system (Model DLT-100; Los Gatos Research, Mountain View, CA, USA) at the Key Laboratory of Hydropedology, Beijing Normal University (precision of $\pm 1.2 \%$ for $\delta \mathrm{D}$ and $\pm 0.3 \%$ for $\delta^{18} \mathrm{O}$ ). The isotopic data from the water extracted from plant tissues were first checked for spectral interference using the Spectral Contamination Identifier (LWIA-SCI) post-processing software (Los Gatos Research, Inc.) because certain stable isotopic ratios of the plant water can be easily affected by organic contamination, such as from methanol and ethanol, and result in erroneous isotopic values (West et al. 2010). The stable isotopic composition was expressed as follows:

$\delta X=\left(R_{\text {sample }} / R_{\text {standard }}-1\right) \times 1000$

where $R_{\text {sample }}$ and $R_{\text {standard }}$ represent the sample of the molar abundance ratios $\left({ }^{18} \mathrm{O} /{ }^{16} \mathrm{O},{ }^{2} \mathrm{H} /{ }^{1} \mathrm{H}\right)$ of the sample and the standard (Vienna Standard Mean Ocean Water), respectively.

The monthly amount-weighed mean of $\delta \mathrm{D}$ and $\delta^{18} \mathrm{O}$ for precipitation was calculated as follows:

$\delta \bar{P}=\frac{\sum_{i}^{n} \delta_{i} \times P P T_{i}}{\sum_{i}^{n} P P T_{i}}$

where $\delta_{i}$ and $P P T_{i}$ represent the isotopic content of an event-based precipitation and the event-based precipitation amount, respectively. 


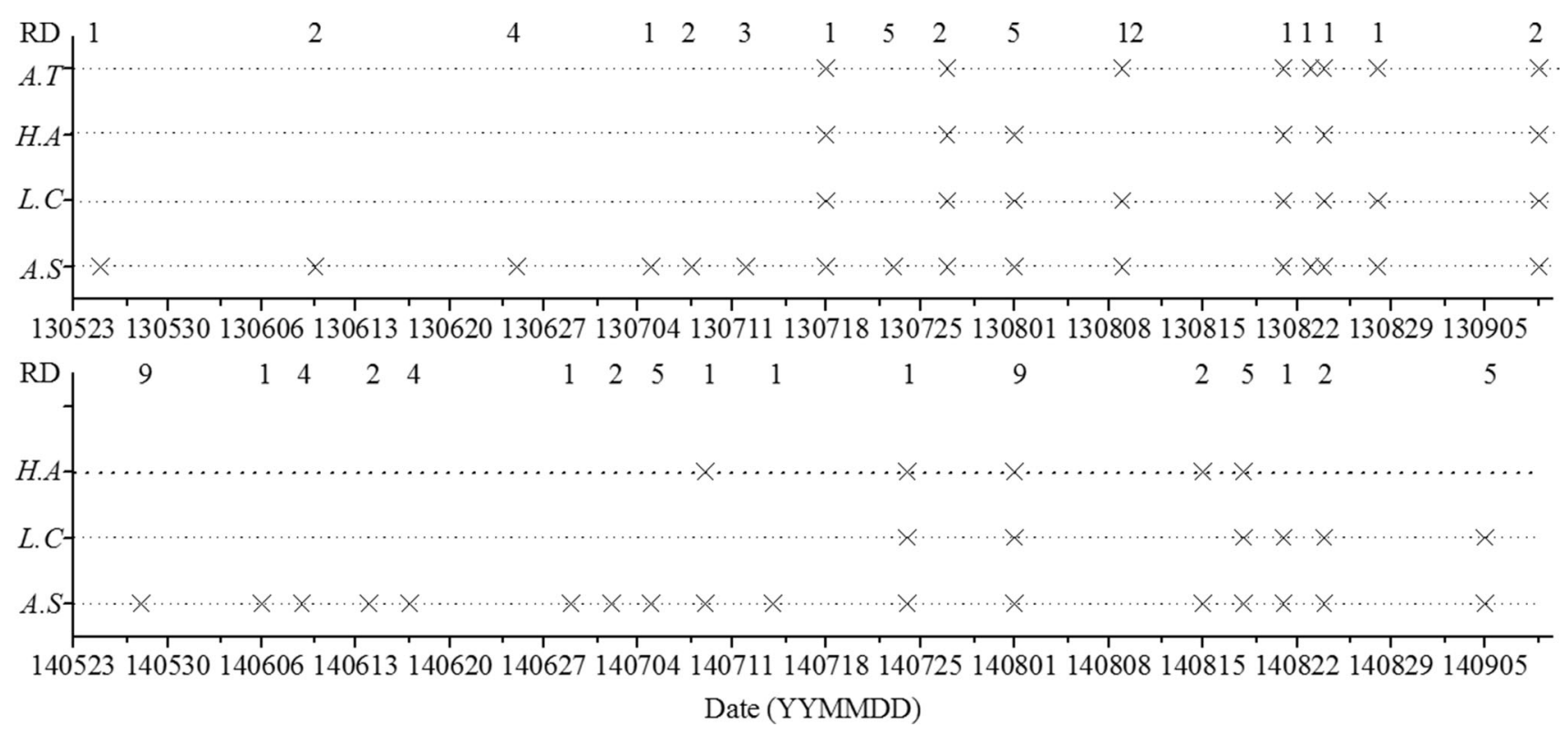

Fig. 2 Temporal distributions of sampling species and rainless days before each sampling date (RD) in 2013-2014. A. splendens (A.S), H. altaicus (H.A), L. chinensis (L.C), A. tanguticum (A.T)

\section{Data analysis}

The deuterium and oxygen- 18 of soil and plant tissue water had similar variations, and thus, the similar trends of relative contribution of soil water to xylem water were obtained from the IsoSource mixing model throughout the growing seasons (Phillips and Gregg 2003). In this study, we analyzed the results from the $\delta \mathrm{D}$ calculation to evaluate the temporal variations of water use patterns by coexisting plants in the alpine grassland community. Based on the variations of the SWC and the isotopic contents of the soil water in the entire soil profile, three potential soil water source layers $(0-10,10-30$ and $30-60 \mathrm{~cm})$ were identified (see below). The isotopic compositions of each soil water layer were determined by the soil water content-weighted mean approach (Snyder and Williams 2003; Liu et al. 2014):

1. Shallow soil layer $(0-10 \mathrm{~cm})$ : the isotopic content and the SWC were highly variable and susceptible to the precipitation pulse inputs and evaporation in dependence on season and depth.

2. Middle soil layer $(10-30 \mathrm{~cm})$ : lower isotopic contents and relatively mild monthly change compared with the shallow soil layer.

3. Deep soil layer $(30-60 \mathrm{~cm})$ : relatively stable variations of isotopic contents and soil water contents were found in this entire soil layer.

The source increment was set at $1 \%$, and the mass balance tolerance was set at $0.1 \%$. Our calculated results were reported as the distribution (i.e., maximum and minimum) of feasible solutions and mean at each sampling date.

To test the difference between $\delta \mathrm{D}$ of the plant water, a two-way analysis of variance (ANOVA) was conducted to detect the significance of the main effects (sampling date and species) and interactions between sampling date and species on the $\delta \mathrm{D}$ of plant water after testing for normality of residuals and homogeneity of variances. Similarly, the temporal variations of the soil water content and isotopic composition were analyzed using a two-way ANOVA with sampling date and depth as factors. All values conformed to normality and sphericity assumptions, and the significance level was set at 0.05. A oneway ANOVA followed by a post hoc Tukey's least significant difference test at $p<0.05$ was used to detect significant differences in the SWC and soil depths, isotopic contents of soil water among soil depths. All the statistical analyses were performed in SPSS 13.0 (SPSS Inc., Chicago, USA).

\section{Results}

\section{Precipitation pattern and isotopic compositions $(\delta \mathrm{D})$ of the precipitation}

According to 55 years of meteorological data from the Gangcha weather station in the study area, high precipitation and temperature occurred during the period between May and September (Fig. 3a). The precipitation events 


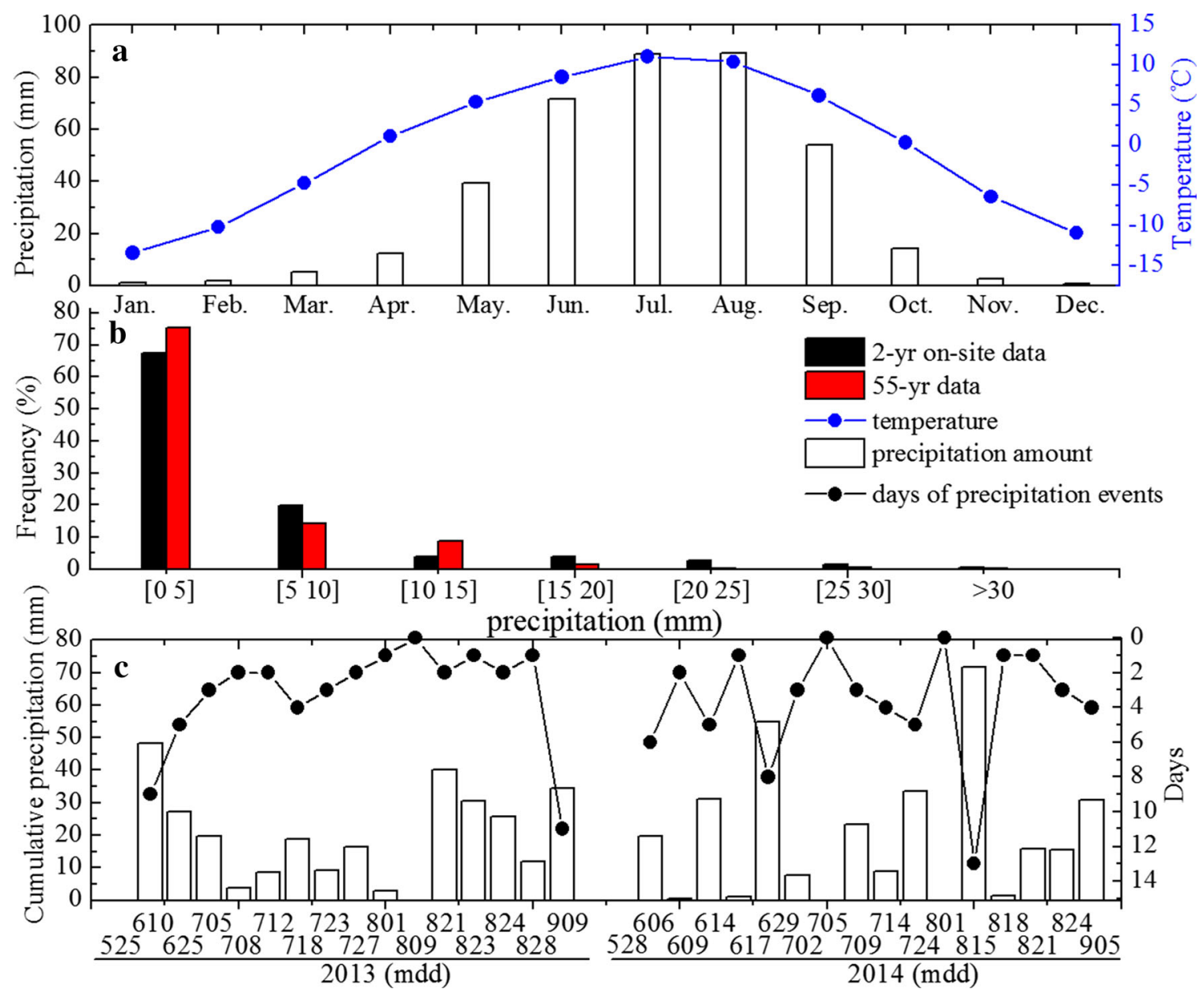

Fig. 3 Distribution of the annual average monthly precipitation amount, air temperature (a), frequency of different precipitation event sizes (b), and cumulative precipitation amount and precipitation events between each sampling date in the study region (c). 55-year

were mainly characterized by several small events (e.g., 0-5 mm) and few large events (e.g., $>30 \mathrm{~mm}$ ) based on both the 55-year data and the 2-year on-site data (Fig. 3b). Heavy precipitation events $(>30 \mathrm{~mm})$ accounted for only a small proportion (2\%), while, of 2- and 55-year data, respectively, precipitation events of $0-5 \mathrm{~mm}$ account for 67.5 and $75.2 \%$ and events of $5-10 \mathrm{~mm}$ accounted for 19.9 and $14.3 \%$ (Fig. 3b). The cumulative precipitation amount between each sampling date varied from $0 \mathrm{~mm}$ (August 9, 2013, and July 5, 2014) to $71.6 \mathrm{~mm}$ (August 15, 2014, Fig. 3c). The occurrence of precipitation events between each sampling date ranged from 0 to 13 days (Fig. 3c).

The event-based isotopic compositions $(\delta \mathrm{D})$ in precipitation exhibited a large fluctuation with high variability of the precipitation amount during the study period (Fig. 4a). The variations of the event-based $\delta \mathrm{D}$ in precipitation had a wide range from 6.13 to $-122.5 \%$ with a monthly average data of precipitation amount and temperature of the Gangcha National Meteorological Observation from 1958 to 2013 and 2-year on-site data from the automatic weather station in the study site from 2013 to 2014. mdd: month day

value of $-38.14 \%$ and more negative $\delta \mathrm{D}$ values in April, May and August. As seen from Fig. 4a, the successive rainfall events with heavy precipitation amounts had relatively negative $\delta \mathrm{D}$ values (e.g., 2013/8/23, $p=25.7 \mathrm{~mm}$, $\delta \mathrm{D}=-64.4 \%$ ) in August 2013 as a result of the precipitation amount effect. Instead, certain rainfall events with small precipitation amounts had relatively less negative $\delta \mathrm{D}$ values due to the strong influence of evaporation enrichment on the isotopic compositions of precipitation during the study period.

\section{Soil water content and isotope contents}

Due to the dual effects of evaporation and precipitation inputs, the soil water content showed great fluctuations among the different soil layers (Figs. 4b, 5). Substantial precipitation inputs into the upper $30-\mathrm{cm}$ soil layers caused a sharp increase in the SWC (e.g., in August, Fig. 4b), 


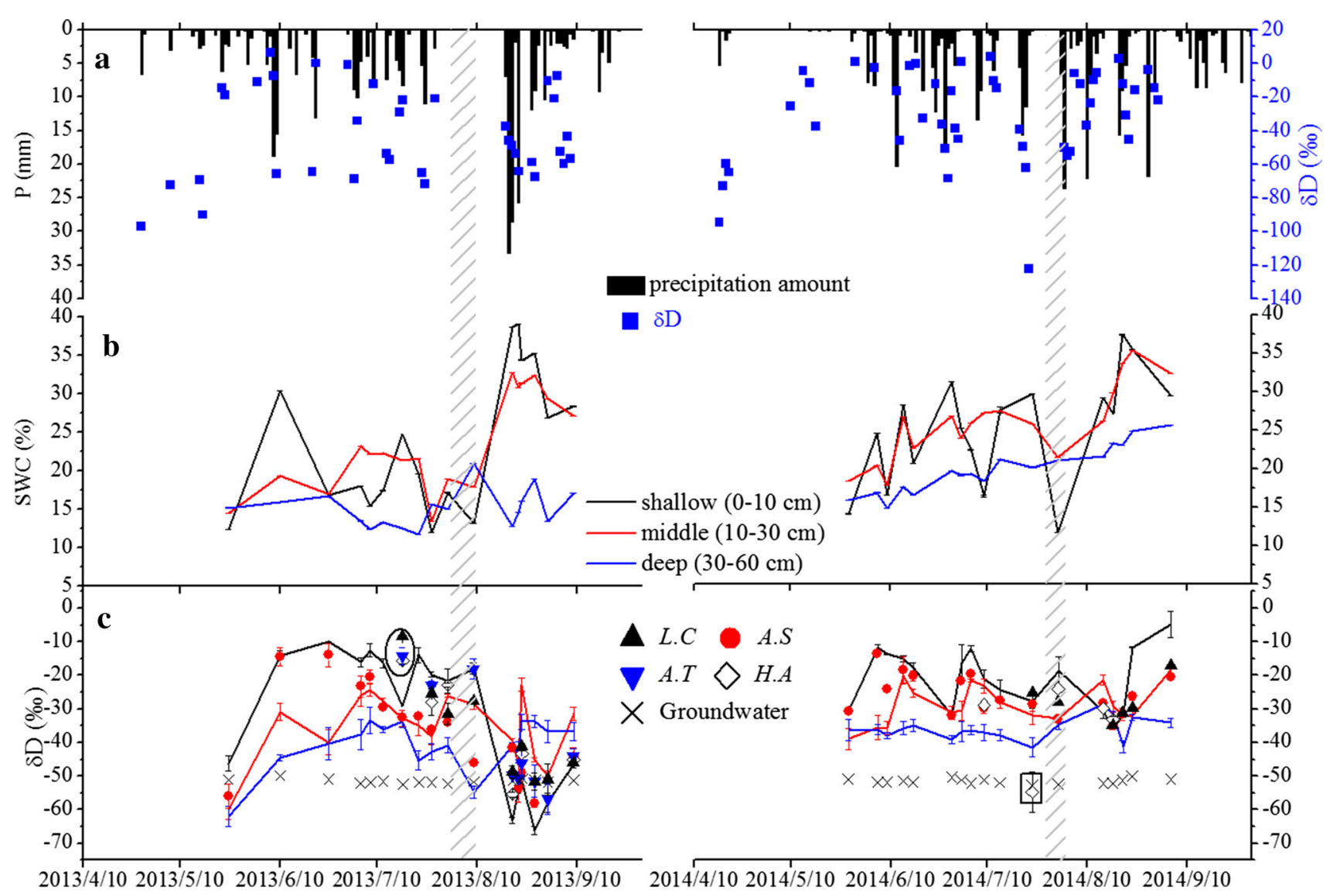

Fig. 4 Temporal variations of precipitation amount (a), gravimetric soil water content (b) and isotopic composition in precipitation, soil water, plant tissue and groundwater (c). Gray filled patterns represent episodes of drought during the growing seasons. Vertical bars represent standard errors. A. splendens (A.S), H. altaicus (H.A), L. chinensis (L.C) and A. tanguticum (A.T) whereas the effect of evaporation resulted in a lower shallow SWC due to long drought in comparison with the middle and deep soil layers (e.g., a 12-day drought from July 28, 2013, to August 9, 2013, and a 9-day drought from July 24, 2014, to August 1, 2014, Fig. 4b with gray filled pattern). Additionally, dynamic variations of volumetric soil water content among soil layers were clearly observed (Fig. 5). The shallow soil water contents $(0-10 \mathrm{~cm})$ showed a sharp increase as the precipitation amount was greater than $10 \mathrm{~mm}$ or with a series of small precipitation events $(<10 \mathrm{~mm})$. There was a typical lag time among the different soil layers, where the shallow soil SWC $(0-10 \mathrm{~cm})$ sensitively respond to the precipitation events inputs, whereas the deep soil SWC (40 and $60 \mathrm{~cm}$ ) exhibited small changes as a result of the lesser influence of the precipitation infiltration and the prolonged episodes of drought (Fig. 5).

There was a significantly mixed effect of sampling date $(p<0.001)$, depth $(p<0.001)$ and interaction between sampling date and depth $(p=0.001)$ on the soil water $\delta \mathrm{D}$ values. The soil water $\delta \mathrm{D}$ values experienced pronounced seasonal changes throughout the growing seasons, with greater fluctuation of $\delta \mathrm{D}$ values in the shallow soil layer $(0-10 \mathrm{~cm})$ and relatively stable variations of $\delta \mathrm{D}$ values in the deep soil layer $(30-60 \mathrm{~cm}$; Fig. 4c). In particular, the shallow soil water $\delta \mathrm{D}$ values were more negative because of the substantial precipitation infiltration with isotopically depleted $\delta \mathrm{D}$ values in late August 2013. The groundwater $\delta \mathrm{D}$ values exhibited no seasonal changes (average $-51.53 \%$ ) during the growing season (Fig. $4 \mathrm{c}$ ). The length of rainless days before each sampling date had significant effects on the evaporation fractionation of the soil water isotopic contents $(p=0.001)$. The strong influences of evaporation resulted in a sharp decrease in the shallow soil SWC and more enriched $\delta \mathrm{D}$ values due to longer rainless days (e.g., 12- or 9-day drought periods in 2013-2014; Fig. 4c). In contrast, the relatively negative isotopic contents in the soil water were found during the shorter sampling periods because of smaller evaporative effects (e.g., 1 day sampling; Figs. 2, 4c).

The isotope contents of water from soil, precipitation, groundwater and plant tissues are presented in Fig. 6. The 


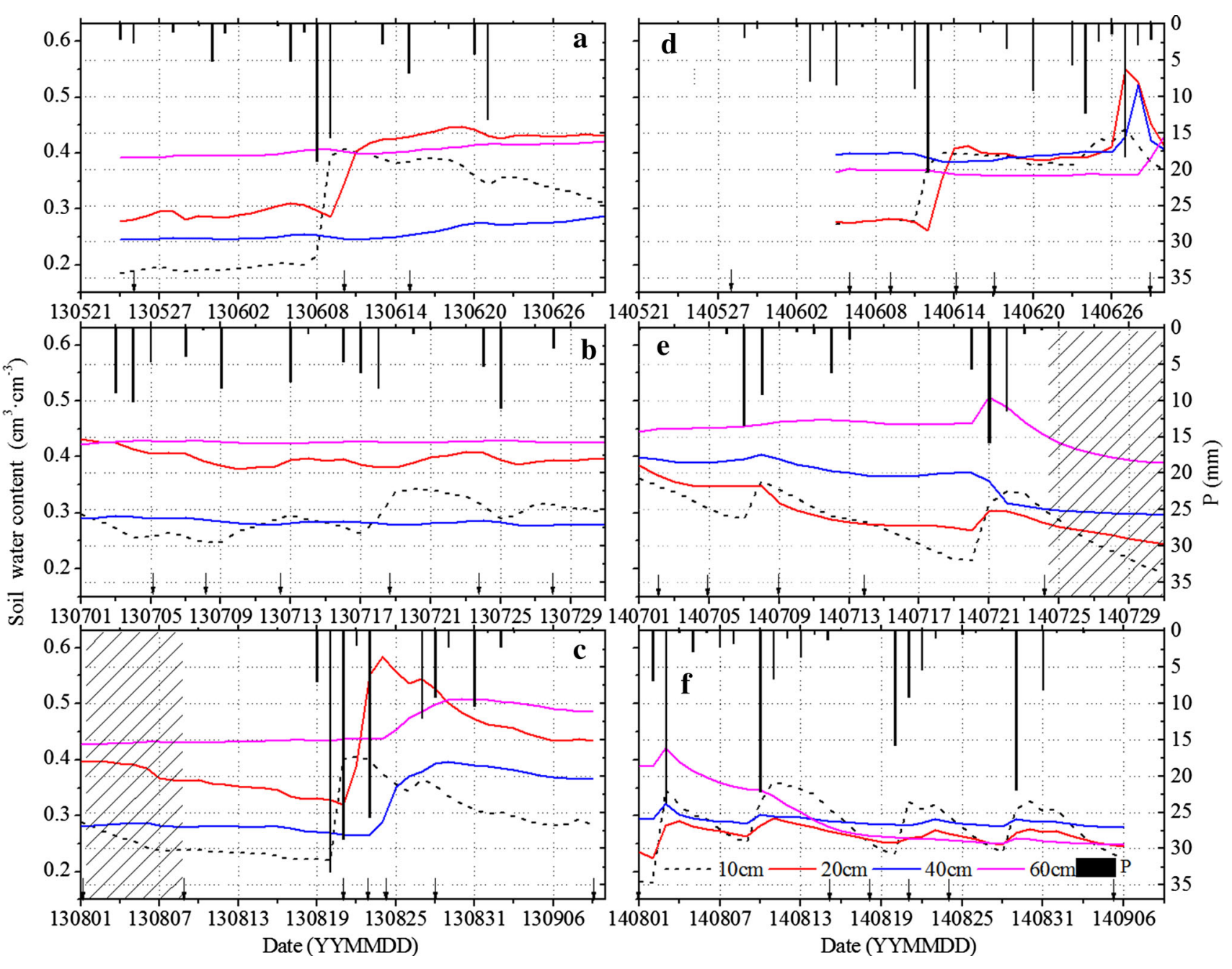

Fig. 5 Dynamic variations of the volumetric soil water content throughout the two growing seasons. Gray filled patterns represent episodes of drought during the growing seasons. The downward arrows represent the sampling events of plant and soil water

isotopic contents of the groundwater are clustered with the LMWL, which reflect the contribution of the precipitation to the recharge of local aquifers in this region. The soil water isotopic values are distributed along and below the right of the local meteoric water line shown as the soil water line (SWL) in Fig. 6.

\section{Proportion of water source used by coexisting plants}

The deuterium isotope contents of the plant tissues changed with season, and their fluctuations are presented in Fig. 4c. The water isotopic contents of plant tissues are significantly affected by the species, date and interaction between species and date $(p<0.001)$. During the early growing season of 2013-2014, the isotopic contents of A. splendens were more negative than during other sampling dates (excluding in late August, 2013). The length of rainless days before each sampling date also had a significant effect on the isotopic contents of plant tissues $(p<0.001)$, which was closely related to the differential soil water sources. Most of the deuterium isotope contents of plant tissues were distributed between the shallow and deep soil water. Surprisingly, the isotopic contents of certain plants water (e.g., H. altaicus, L. chinensis and A. tanguticum) were even more enriched than the shallow soil water (Fig. 4c) or more depleted than the deep soil water ( $H$. altaicus) (Fig. 4c). Additionally, all the isotopic values of the plant tissue water were clustered around the soil water line (SWL; Fig. 6), which indicates that the plant tissue water was primarily acquired from soil water.

The proportion of water uptake by coexisting species calculated by the mixing isotope IsoSource model is shown in Fig. 7. The model results showed that herbs (H. altaicus and $A$. tanguticum) mainly depend on shallow soil water throughout the growing seasons, whereas A. splendens and L. chinensis could alter their functional root zones to absorb water from different soil layers. At the onset of the growing seasons, more than $80 \%$ of water from the 


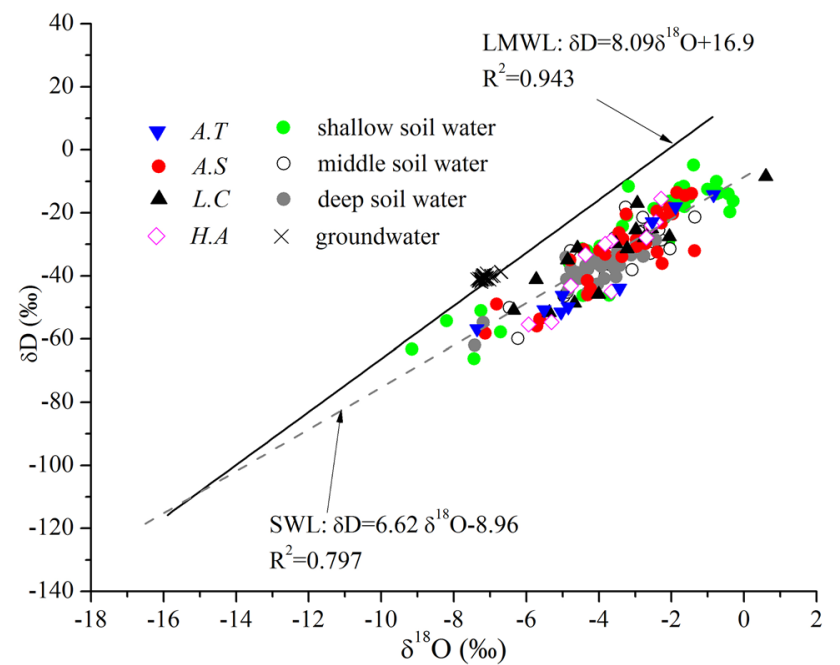

Fig. $6 \delta D-\delta^{18} \mathrm{O}$ plot of soil water, precipitation and groundwater in comparison with plant tissue water collected at the study site shown with the local meteoric water line (LMWL, solid line) and the soil water line (SWL, dashed line). A. splendens (A.S), H. altaicus (H.A), L. chinensis (L.C), and A. tanguticum (A.T) shallow soil layers was used by A. splendens (May and June, Fig. 7a). In July and early August, A. splendens progressively shifted its water source from the shallow soil layer to the middle or deep soil water as the length of rainless days increased between sampling dates (e.g., August 9, 2013, and August 1, 2014). In late August and September 2013, A. splendens absorbed a high proportion of water from the shallow soil layer because of the increase of the size and duration of the precipitation pulse. However, A. splendens depended on the water from the middle and deep soil layers on August 24 and September 5, 2014, as a result of a long-time rainless days. Similar to $A$. splendens, L. chinensis mostly used a high proportion of shallow soil water throughout the growing seasons, but it switched the water sources from shallow to middle soil layers during extended drought periods (Fig. 7b). However, regardless of the length of rainless days before each sampling date, herbs (H. altaicus and A. tanguticum) used a high proportion of water from the shallow soil layers (Fig. 7c-e).
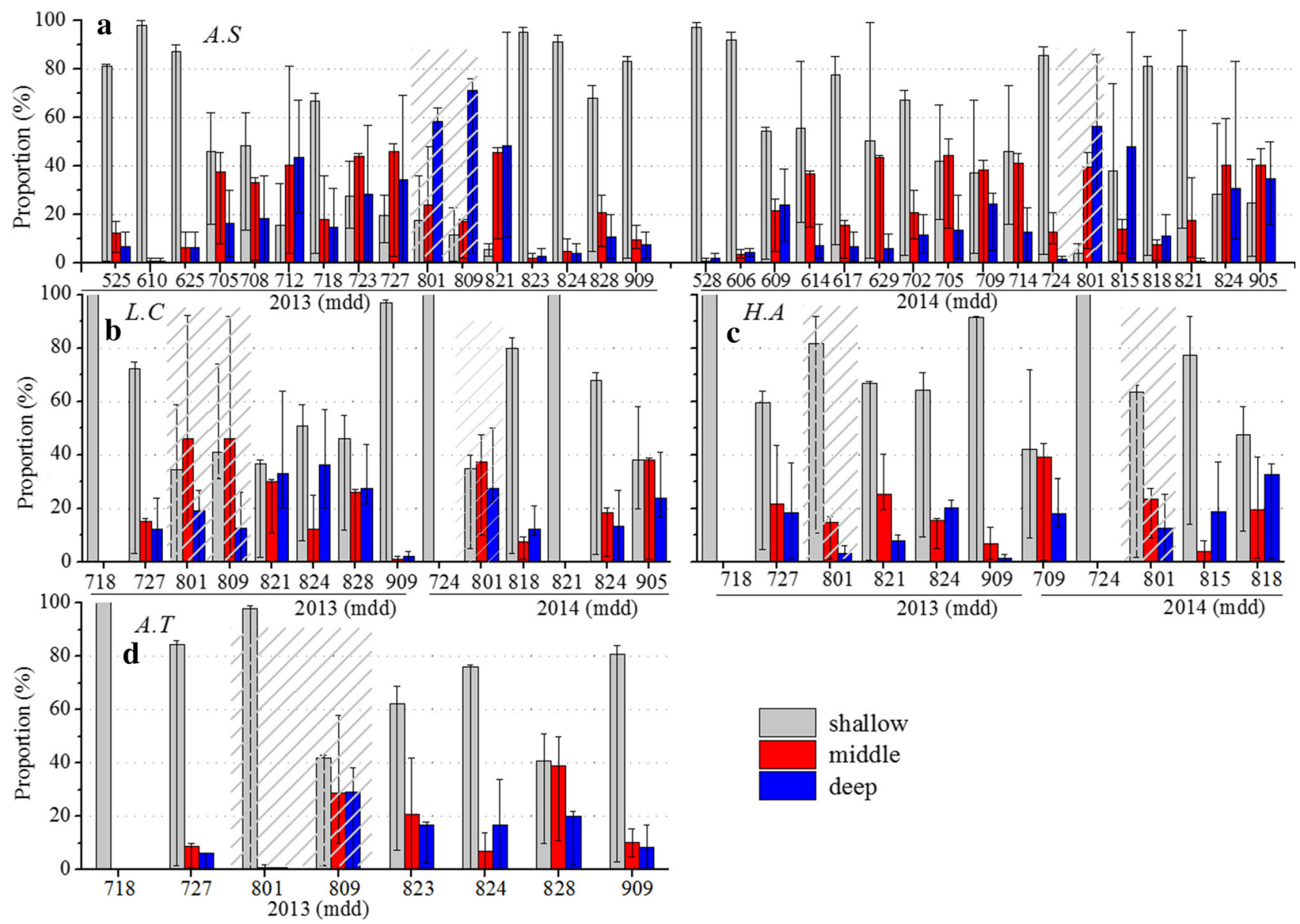

Fig. 7 Proportion of water sources utilization by coexisting plants during the growing seasons of 2 years. Gray filled patterns represent episodes of drought during the growing seasons. The column height represents the mean proportion of water use, and vertical bars

represent the range of maximum and minimum water use. Both are derived from the mixing isotope IsoSource model. A. splendens (A.S), L. chinensis (L.C), H. altaicus (H.A) and A. tanguticum (A.T). mdd: month day 


\section{Discussion}

\section{Soil water availability and water sources used by coexisting plants}

The shallow soil moisture $(0-10 \mathrm{~cm})$ showed the highest variations (Fig. $4 \mathrm{~b}, 5$ ), and simultaneously, the $\delta \mathrm{D}$ values fluctuated more than those of the deep soil layer $(30-60 \mathrm{~cm})$ during the entire growing seasons. This pattern is the result of both precipitation pulse inputs and evaporative enrichment in shallow soil layer $(0-10 \mathrm{~cm}$ ) (Allison and Barnes 1983; Asbjornsen et al. 2007). The lower slope of the SWL also indicated that the isotopic compositions of the soil water experienced a strong evaporative enrichment (Fig. 6). The $\delta \mathrm{D}$ values of the plant tissues varied during the growing season, which suggests that they are largely associated with the water sources utilized by plants (Fig. 4b). The isotopically depleted contents of A. splendens were found at the onset of growing seasons because snow water with isotopically depleted contents was recharged into the soil layers in early May. Meanwhile, the isotopically depleted contents of plants water were contributed by heavy precipitation events in late August 2013, which indicates that recent precipitation pulses were the main water sources utilized by the studied plants.

The dominant coexisting plants showed different responses to the use of soil moisture pulse from precipitation events that differed in precipitation pulse size and the length of rainless days before each sampling date, as indicated by the changes in the deuterium content of plant tissues and the uptake proportions (Figs. 4c, 7). At the onset of the growing seasons, with a gradual increase in precipitation amount and air temperature (before July, Figs. 3, 5), A. splendens used a sizeable proportion of water from the shallow soil without evidently switching water sources. These results are consistent with the finding of Asbjornsen et al. (2007), who demonstrated that all the plant species absorbed water from shallow soil water during the early growing season in Central Iowa, USA. These differential water use patterns were closely linked with high soil water availability and a proper soil temperature favorable for surficial roots proliferation and elongation to acquire water and nutrients in the early growing seasons (Drennan and Nobel 1998; Williams and Ehleringer 2000).

In contrast to the early growing season, A. splendens exhibited its capacity to flexibly switch the potential water source between shallow and deep soil layers at the peak of the growing seasons (July and August; Fig. 7a). This switch is probably due to a trade-off between the activity of the shallow and deep roots, where active shallow roots were restricted by high soil temperature and low soil water availability (Williams and Ehleringer 2000). As the interspecific competition within the community intensified and the shallow soil water availability declined during drought periods, $A$. splendens flexibly shifted the water use from shallow to deep soil layers to sustain its transpiration and produce high aboveground biomass and growth (Fig. 7a with gray filled pattern). Several other studies conducted in arid regions concluded that grasses (e.g., bunchgrass Bouteloua gracilis, in Northeast Colorado) and forbs (in eastern Kansas, USA) exhibited a great capacity of ecological plasticity that plants can shift the depth of water sources in response to water availability (Dodd et al. 1998; Asbjornsen et al. 2007; Nippert and Knapp 2007). L. chinensis showed a relatively low plasticity to shift its water source from shallow to middle soil layers (Fig. 7b), whereas other herbs (H. altaicus and A. tanguticum) predominantly depended on the shallow soil water during the growing seasons (Fig. 7c-e). This water use pattern of herbs can intensify the inter- and intraspecific competition for limited shallow soil water and nutrients with grasses and induce grasses to use deep soil water to avoid the direct competitions with herbs (Kulmatiski and Beard 2013; Rossatto et al. 2013; Hoekstra et al. 2014). The deuterium contents of grass and herbs were more positive than those of the precipitation and shallow soil water on certain sampling dates (Fig. 4c), which reflect that the water uptake from surface soil $(<10 \mathrm{~cm})$ had experienced a strong evaporative enrichment (Asbjornsen et al. 2007; Eggemeyer et al. 2009). These differential water use patterns of the studied plant species may reflect their high drought tolerance with superior acquisition of resources with high assimilation and water exchange rates, wellprotected meristems close to or in the ground and the option of dormancy if conditions are less favorable (Craine et al. 2012; Prechsl et al. 2015).

Previous studies have demonstrated that a large precipitation event favors deep-rooted shrubs over the shallow-rooted grasses in arid ecosystems (Sala and Lauenroth 1982; Dodd et al. 1998; Cheng et al. 2006). However, Schwinning et al. (2003) have reported that dominant cold desert plants do not experience the typical water source partitioning response to the size of precipitation events in southern Utah, USA. This outcome is consistent with our results, which indicates that large events (e.g., from 8/21/ 2013 to 8/23/2013, Fig. 5c) or long-lasting small events (e.g., cumulative amount of $71.6 \mathrm{~mm}$ from $8 / 2 / 2014$ to 8/14/2014, Figs. 3c, 5f) include all the plants to utilize shallow soil waters. Heavy precipitation amounts result in a great infiltration of water into deep soil layers and increase the soil moisture (Fig. 5), which plays a crucial role in sustaining deep-root plants' transpiration and growth (e.g., A. splendens) during drought periods (Noy-Meir 1973; Ogle and Reynolds 2004). In the late growing seasons 
(September), the grass L. chinensis and several herbs acquired a large proportion of water from the shallow soil layer $(0-10 \mathrm{~cm})$. Instead, A. splendens used water mostly from the middle and deep soil layers, which shows that the most active root zones were limited to the middle and deep soil layers for A. splendens (Eggemeyer et al. 2009). Additionally, we found that the $\delta \mathrm{D}$ values of plant tissues appeared to be well matched with those of the groundwater on certain sampling dates (Fig. 4c). However, all the studied plants used water from the shallow soil layer as a result of high shallow soil water availability that was enough for their survival. Likewise, the plants did not use groundwater due to the limitation of maximum rooting depth.

\section{Implications of the interspecific competition for soil moisture pulse use}

The contrasting water use patterns among species contribute to minimize the competition for ephemeral soil moisture pulses during prolonged drought periods (Williams and Ehleringer 2000; Eggemeyer et al. 2009; Kambatuku et al. 2013). In this study, we found that the responses of the proportion of water use by dominant coexisting plants to the soil moisture pulses were significantly different (discussion in "Precipitation pattern and isotopic compositions ( $\delta \mathrm{D})$ of the precipitation" section), which suggests that the plant interspecific competition for water was intensive when the shallow soil water $(0-10 \mathrm{~cm})$ was limited. Over the past 55 years, the occurrence of small precipitation events was the highest $(<10 \mathrm{~mm}$, Fig. 3), which could result in significant ecological effects on the ecosystem metabolic activity and water nutrient cycles in shallow soil layers (Sala and Lauenroth 1982; Cheng et al. 2006; Jenerette et al. 2008). The responses of plant growth to the soil moisture pulses were influenced by precipitation duration, size and dry periods between events (Reynolds et al. 2004; Cheng et al. 2006) and resulted in water stress for different plant functional types. Yang et al. (2011) have reported that $C$. squarrosa with negative leaf potential may delay the start of growth to compensate for the water stress, e.g., low plasticity for water extraction, whereas L. chinensis showed a high plasticity to extract more water from deep winter moisture than other species in Inner Mongolia, China. Lin et al. (1996) have demonstrated that species capable of utilizing summer rains should be at a competitive advantage over those that are incapable in the Colorado Plateau. These results are consistent with the findings of Ehleringer et al. (1991), who observed that herbaceous perennials that depended on summer rains experienced a competitive advantage over most of the woody perennials. Hence, the grass $A$. splendens and $L$. chinensis with flexible water use patterns had competitive advantages over the herbs (H. altaicus and A. tanguticum), which solely rely on shallow soil waters in the Qinghai Lake. Additionally, A. splendens patches have the function of accumulating resources (e.g., water, nutrients and salt in the rooting zones) and, thus, build competing habitats with other associated species by accumulating and moving salt to the upper root zones during the drier periods with an electromagnetic induction method (unpublished data). This function of $A$. splendens favors its predominance and competitive advantage over other associated species in the Qinghai Lake.

Furthermore, future predictions, such as changes in the amount, distribution, frequency and intensity of precipitation, particularly in grasslands, may have important consequences for further altering the competitive relationship among coexisting species and for affecting ecosystem processes (Walther et al. 2002; Craine et al. 2012). In the study region, the precipitation patterns have experienced considerable alterations in recent decades, for example, the increasing trend of small and large precipitation events, the longest period of consecutive rainless days and the total number of days with more than ten consecutive rainless days from the 1960s to the 1990s (Sun et al. 2007). Hence, we predict that if frequent and small events or occasional and large events occur in the peak of the growing season, the upper roots of all the coexisting plants will likely be active and favor all the coexisting plants dependence on shallow soil waters. If long consecutive rainless days occur occasionally, the shallow soil water will be reduced, which might more greatly affect the water stress of herbs $(H$. altaicus and A. tanguticum) than that of grasses ( $A$. splendens and L. chinensis). Thus, the precipitation patterns could affect the water use patterns of coexisting plants for adapting to the altered environments, which might have further implications on the distributions of grassy species in the alpine, semiarid grasslands. Therefore, from a long-term perspective, the highly flexible water use patterns by $A$. splendens could potentially explain its dominance across a broad range of alpine conditions around the Qinghai Lake.

\section{Conclusions}

In this study, we used the stable deuterium isotopes to examine the dynamics of water use by dominant coexisting plants and their response to the soil water fluctuations subject to precipitation pulses. The effect of evaporation with the long rainless days on isotopic contents and shallow soil SWC was stronger than that in the other soil layers, resulting in the enriched deuterium composition and low SWC in the shallow soil layer $(0-10 \mathrm{~cm})$. In contrast, the relatively negative $\delta \mathrm{D}$ values and high $\mathrm{SWC}$ in the 
shallow soil layer were influenced by the substantial precipitation infiltration with isotopically depleted isotopic values according to large precipitation events or the short rainless days. The coexisting plants exhibited contrasting water use patterns in response to the soil moisture pulses throughout the 2-year growing seasons. The deep-rooted $A$. splendens used the shallow soil water at the early growing season, while it absorbed water from deep soil layers when there was an increase in rainless days before each sampling date at the peak of the growing season. The shallow-rooted L. chinensis also had the capacity to use the water sources with certain flexibility and shifted its water use between shallow and middle soil layers. Large events substantially recharged into the shallow soil layer, which was predominantly absorbed by grasses (A. splendens and L. chinensis). In addition, despite periodic droughts or occasionally high soil water content, the herbs (H. altaicus and A. tanguticum) mainly used water from the shallow soil layer. The degree of the potential water source use by coexisting plants was highly dependent on the root distributions and the soil water availability. The contrasting water use patterns by coexisting plants mirrored their adaptations to the high fluctuations of soil moisture pulses within waterlimited ecosystems.

Acknowledgments We thank Zongchao Li and Yifei Zhou for their field assistance in this study. The study was financially supported by the National Natural Science Foundation of China (NSFC 41130640, 91425301, 41321001 and 41301013), the PCSIRT (IRT_15R06), and projects from the State Key Laboratory of Earth Surface Processes and Resource Ecology. Finally, we are very grateful to three anonymous reviewers for their valuable discussions and comments on the early version of the manuscript.

\section{References}

Aguiar MR, Sala OE (1999) Patch structure, dynamics and implications for the functioning of arid ecosystems. Trends Ecol Evol 14:273-277. doi:10.1016/S0169-5347(99)01612-2

Allison G, Barnes C (1983) Estimation of evaporation from nonvegetated surfaces using natural deuterium. Nature 301:143-145. doi:10.1038/301143a0

An Z, Colman SM, Zhou W, Li X, Brown ET, Jull AT, Cai Y, Huang Y, Lu X, Chang H (2012) Interplay between the Westerlies and Asian monsoon recorded in Lake Qinghai sediments since $32 \mathrm{ka}$. Sci Rep. doi:10.1038/srep00619

Asbjornsen H, Mora G, Helmers MJ (2007) Variation in water uptake dynamics among contrasting agricultural and native plant communities in the Midwestern US. Agric Ecosyst Environ 121:343-356. doi:10.1016/j.agee.2006.11.009

Barnard RL, de Bello F, Gilgen AK, Buchmann N (2006) The $\delta 180$ of root crown water best reflects source water $\delta 18 \mathrm{O}$ in different types of herbaceous species. Rapid Commun Mass Spectrom 20:3799-3802

Chen G, Peng M (1993) Community characteristics and distribution laws of Achnatherum splendens in Qinghai Province. Acta Botan Boreali Occident Sin 13:154-162 (in Chinese with English abstract)
Cheng X, An S, Li B, Chen J, Lin G, Liu Y, Luo Y, Liu S (2006) Summer rain pulse size and rainwater uptake by three dominant desert plants in a desertified grassland ecosystem in northwestern China. Plant Ecol 184:1-12. doi:10.1007/s11258-005-9047-6

Chesson P, Gebauer RL, Schwinning S, Huntly N, Wiegand K, Ernest MS, Sher A, Novoplansky A, Weltzin JF (2004) Resource pulses, species interactions, and diversity maintenance in arid and semi-arid environments. Oecologia 141:236-253. doi:10. 1007/s00442-004-1551-1

Craine JM, Engelbrecht BMJ, Lusk CH, McDowell NG, Poorter H (2012) Resource limitation, tolerance, and the future of ecological plant classification. Front Plant Sci 3:246. doi:10.3389/fpls. 2012.00246

Dai Y, Zheng X-J, Tang L-S, Li Y (2015) Stable oxygen isotopes reveal distinct water use patterns of two Haloxylon species in the Gurbantonggut Desert. Plant Soil 389:73-87. doi:10.1007/ s11104-014-2342-z

Dodd M, Lauenroth W, Welker J (1998) Differential water resource use by herbaceous and woody plant life-forms in a shortgrass steppe community. Oecologia 117:504-512. doi:10.1007/s004420050686

Drennan PM, Nobel PS (1998) Root growth dependence on soil temperature for Opuntia ficus-indica: influences of air temperature and a doubled $\mathrm{CO}_{2}$ concentration. Funct Ecol 12:959-964. doi:10.1046/j.1365-2435.1998.00276.x

Eggemeyer KD, Awada T, Harvey FE, Wedin DA, Zhou X, Zanner CW (2009) Seasonal changes in depth of water uptake for encroaching trees Juniperus virginiana and Pinus ponderosa and two dominant $\mathrm{C} 4$ grasses in a semiarid grassland. Tree Physiol 29:157-169. doi:10.1093/treephys/tpn019

Ehleringer JR, Phillips SL, Schuster WSF, Sandquist DR (1991) Differential utilization of summer rains by desert plants. Oecologia 88:430-434. doi:10.1007/BF00317589

Hoekstra N, Finn J, Hofer D, Lüscher A (2014) The effect of drought and interspecific interactions on depth of water uptake in deepand shallow-rooting grassland species as determined by $\delta 18 \mathrm{O}$ natural abundance. Biogeosciences 11:4493-4506. doi:10.5194/ bg-11-4493-2014

Huai H, Wei W, Zhang Y (2008) Characteristics of the Achnatherum splendens community along the Qinghai-Tibet Railway, China. Front Biol China 3:477-483 (in Chinese with English abstract)

Jenerette GD, Scott RL, Huxman TE (2008) Whole ecosystem metabolic pulses following precipitation events. Funct Ecol 22:924-930. doi:10.1111/j.1365-2435.2008.01450.x

Kambatuku JR, Cramer MD, Ward D (2013) Overlap in soil water sources of savanna woody seedlings and grasses. Ecohydrology 6:464-473. doi:10.1002/eco.1273

Kulmatiski A, Beard K (2013) Root niche partitioning among grasses, saplings, and trees measured using a tracer technique. Oecologia 171:25-37. doi:10.1007/s00442-012-2390-0

Lin G, Phillips S, Ehleringer J (1996) Monosoonal precipitation responses of shrubs in a cold desertcommunity on the Colorado Plateau. Oecologia 106:8-17. doi:10.1007/BF00334402

Liu W, Wang P, Li J, Liu W, Li H (2014) Plasticity of source-water acquisition in epiphytic, transitional and terrestrial growth phases of Ficus tinctoria. Ecohydrology 7:1524-1533. doi:10. 1002/eco.1475

Ludwig JA, Wilcox BP, Breshears DD, Tongway DJ, Imeson AC (2005) Vegetation patches and runoff-erosion as interacting ecohydrological processes in semiarid landscapes. Ecology 86:288-297. doi:10.1890/03-0569

Montaña C, Cavagnaro B, Briones O (1995) Soil water use by coexisting shrubs and grasses in the Southern Chihuahuan Desert, Mexico. J Arid Environ 31:1-13. doi:10.1006/jare.1995.0043

Nippert JB, Knapp AK (2007) Linking water uptake with rooting patterns in grassland species. Oecologia 153:261-272. doi:10. 1007/s00442-007-0745-8 
Noy-Meir I (1973) Desert ecosystems: environment and producers. Annu Rev Ecol Syst 4:25-51. doi:10.2307/2096803

Ogle K, Reynolds J (2004) Plant responses to precipitation in desert ecosystems: integrating functional types, pulses, thresholds, and delays. Oecologia 141:282-294. doi:10.1007/s00442-004-15075

Phillips DL, Gregg JW (2003) Source partitioning using stable isotopes: coping with too many sources. Oecologia 136:261-269. doi:10.1007/s00442-003-1218-3

Prechsl U, Burri S, Gilgen A, Kahmen A, Buchmann N (2015) No shift to a deeper water uptake depth in response to summer drought of two lowland and sub-alpine C3-grasslands in Switzerland. Oecologia 177:97-111. doi:10.1007/s00442-0143092-6

Ramírez DA, Querejeta JI, Bellot J (2009) Bulk leaf $\delta 180$ and $\delta 13 C$ reflect the intensity of intraspecific competition for water in a semi-arid tussock grassland. Plant Cell Environ 32:1346-1356. doi:10.1111/j.1365-3040.2009.02002.x

Reynolds J, Kemp P, Ogle K, Fernández R (2004) Modifying the 'pulse-reserve' paradigm for deserts of North America: precipitation pulses, soil water, and plant responses. Oecologia 141:194-210. doi:10.1007/s00442-004-1524-4

Rossatto DR, de Carvalho Ramos Silva L, Villalobos-Vega R, Sternberg LdSL, Franco AC (2012) Depth of water uptake in woody plants relates to groundwater level and vegetation structure along a topographic gradient in a neotropical savanna. Environ Exp Bot 77:259-266. doi:10.1016/j.envexpbot.2011.11. 025

Rossatto DR, da Silveira Lobo Sternberg L, Franco AC (2013) The partitioning of water uptake between growth forms in a Neotropical savanna: do herbs exploit a third water source niche? Plant Biology 15:84-92. doi:10.1111/j.1438-8677.2012. 00618.x

Sala OE, Lauenroth WK (1982) Small rainfall events: an ecological role in semiarid regions. Oecologia 53:301-304. doi:10.1007/ BF00389004

Schwinning S, Starr BI, Ehleringer JR (2003) Dominant cold desert plants do not partition warm season precipitation by event size. Oecologia 136:252-260. doi:10.1007/s00442-003-1255-y

Snyder KA, Williams DG (2003) Defoliation alters water uptake by deep and shallow roots of Prosopis velutina (Velvet Mesquite). Funct Ecol 17:363-374. doi:10.1046/j.1365-2435.2003.00739.x
Snyder KA, Donovan LA, James JJ, Tiller RL, Richards JH (2004) Extensive summer water pulses do not necessarily lead to canopy growth of Great Basin and northern Mojave Desert shrubs. Oecologia 141:325-334. doi:10.1007/s00442-003-14034

Sun Y, Li X, Xu H (2007) Daily precipitafion and temperature variations in Qinghai Lake watershed in recent 40 years. Arid Metorol 25:7-13 (in Chinese with English abstract)

Walther G-R, Post E, Convey P, Menzel A, Parmesan C, Beebee TJC, Fromentin J-M, Hoegh-Guldberg O, Bairlein F (2002) Ecological responses to recent climate change. Nature 416:389-395. doi: $10.1038 / 416389$ a

West AG, Patrickson SJ, Ehleringer JR (2006) Water extraction times for plant and soil materials used in stable isotope analysis. Rapid Commun Mass Spectrom 20:1317-1321. doi:10.1002/rcm.2456

West AG, Goldsmith GR, Brooks PD, Dawson TE (2010) Discrepancies between isotope ratio infrared spectroscopy and isotope ratio mass spectrometry for the stable isotope analysis of plant and soil waters. Rapid Commun Mass Spectrom 24:1948-1954. doi: $10.1002 / \mathrm{rcm} .4597$

Williams DG, Ehleringer JR (2000) Intra-and interspecific variation for summer precipitation use in pinyon-juniper woodlands. Ecol Monogr 70:517-537. doi:10.1890/0012-9615

Wu H, Li X-Y, Jiang Z, Chen H, Zhang C, Xiao X (2016) Contrasting water use pattern of introduced and native plants in an alpine desert ecosystem, Northeast Qinghai-Tibet Plateau, China. Sci Total Environ 542(Part A):182-191. doi:10.1016/j.scitotenv. 2015.10.121

Xu H, Li Y (2006) Water-use strategy of three central Asian desert shrubs and their responses to rain pulse events. Plant Soil 285:5-17. doi:10.1007/s11104-005-5108-9

Yang H, Auerswald K, Bai Y, Han X (2011) Complementarity in water sources among dominant species in typical steppe ecosystems of Inner Mongolia, China. Plant Soil 340:303-313. doi:10.1007/s11104-010-0307-4

Zhou G, Chen G, Zhao Y, Wang S, Li W, Sun J, Peng M (2002) Study on Achnatherum splendens community characteristics and species diversity around Qinghai Lake. Acta Botan Boreali Occidental Sin 23:1956-1962 (in Chinese with English abstract) 